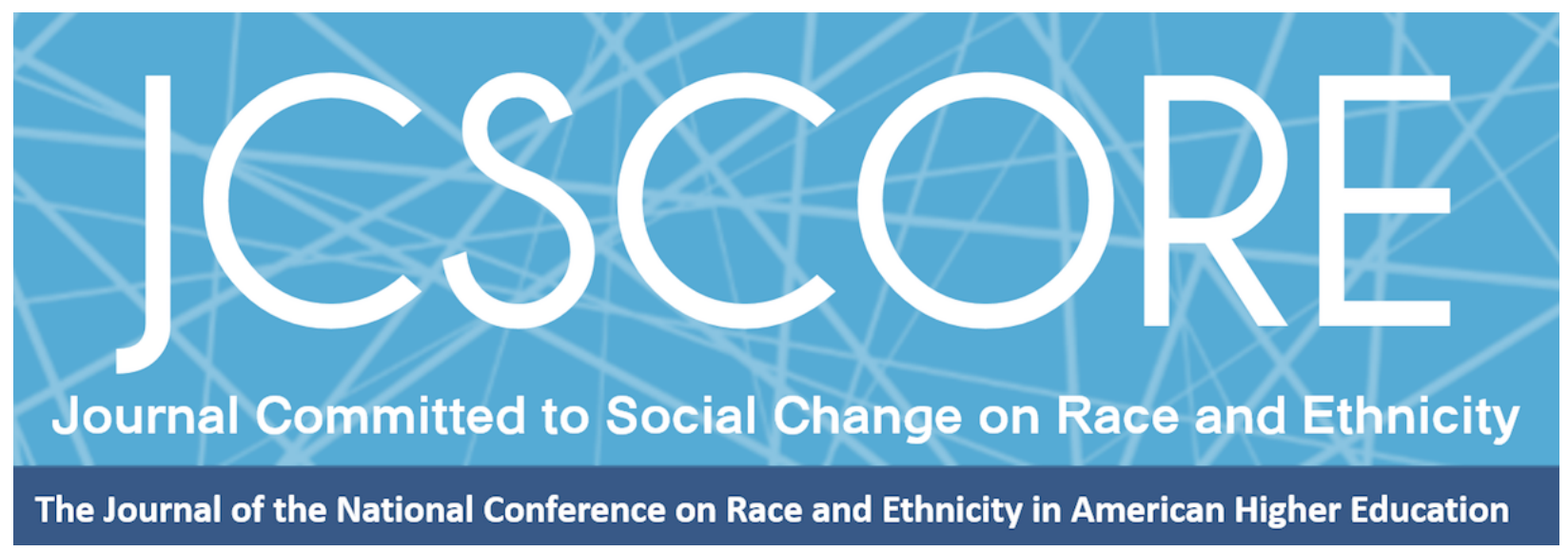

\title{
DISABILITY JUSTICE, RACE, AND EDUCATION
}

\author{
Lissa D. Ramirez-Stapleton \\ California State University Northridge \\ Lisette E. Torres \\ Nebraska Wesleyan University \\ Anna Acha \\ North Carolina State University \\ Ashlee McHenry \\ California State University, Northridge
}

Journal Committed to Social Change on Race and Ethnicity

Volume 6, Issue 1 | 2020

Copyright and Open Access

(c) 2020 Lissa D. Ramirez-Stapleton, Lisette E. Torres, Anna Acha, \& Ashlee McHenry (c) $(1)$ (8)

This work is licensed under a Creative Commons Attribution-NonCommercial-ShareAlike 4.0 International License. Permission of the authors is required for distribution and for all derivative works, including compilations and translations. Quoting small sections of text is allowed as long as there is appropriate attribution and the article is used for non-commercial purposes.

The Journal Committed to Social Change on Race and Ethnicity (ISSN 2642-2387) is published by the National Conference on Race and Ethnicity (NCORE), a production of the University of Oklahoma, in partnership with the University of Oklahoma Libraries. 


\title{
Disability Justice, Race, and Education
}

\author{
Lissa D. Ramirez-Stapleton \\ California State University Northridge \\ Lisette E. Torres \\ Nebraska Wesleyan University \\ Anna Acha ${ }^{1}$ \\ North Carolina State University \\ Ashlee McHenry ${ }^{1}$ \\ California State University, Northridge
}

\begin{abstract}
This special issue pushes for BIPOC communities and intersectional centered perspectives on disability and Deaf communities within higher education as a way to expand our understanding of disabled and Deaf communities' lives. Keeping in mind, that race, disability and Deaf life in higher education are at the heart of this special issue, the articles provide a variety of topics and guiding questions to serve as a starting point for readers' thinking.
\end{abstract}

The current sociopolitical climate in the U.S. - where marginalized communities are constantly under threat of institutional violence (e.g., deportation centers, police violence, healthcare policies, lack of information, lack of emergency response to natural disasters) - has encouraged disabled Black, Indigenous, and People of Color (BIPOC) scholar-activists to stay dedicated to $\mathrm{CRiT}^{2}$ walking (Hughes \& Giles, 2010) in their fight for their communities. New movements have emerged, such as the Disabled Latinx ${ }^{3}$ Movement, the NeuroDiversity Movement and Language Equality and Acquisition for

\footnotetext{
${ }^{1}$ Anna Acha and Ashlee McHenry served as junior Editors for this special issue. They worked behind the scenes learning about the process of writing and publishing and supporting scholars.

${ }^{2}$ The CRT in CRiT stands for Critical Race Theory while the small "i" is meant to convey the metaphor of intellectual and physical activity (dancing or walking), supported by the tenets of CRT.

${ }^{3}$ The term Latinx is used throughout this issue to be inclusive of Latin American people who are gender non-conforming (Salinas \& Lozano, 2019).
} 
Journal Committed to Social Change on Race and Ethnicity | Volume 6, Issue 1 | 2020

Deaf Kids (LEAD-K) movement. There are community activists at all levels, including: Sins Invalid ${ }^{4}$, Ramp Your Voice! with Vilissa, ${ }^{5}$ and ADAPT ${ }^{6}$. These organizations and virtual activist networks are led by knowledge producers who are unrecognized by those in the academy, since the Ivory Tower tends to privilege capitalistic measures of success and dominant ways of knowing and being. These scholar-activists, many of who identify as queer Women of Color, centralize intersectionality (Crenshaw, 1991) and grapple with how to best use it to lead their organizations, create actions around particular social issues, and engage in solidarity work across difference. Academics and activists in higher education have an opportunity to learn from these grassroots thinkers, to create and foster liberatory educational spaces.

For example, Patty Berne from Sins Invalid, a disability justice performance group, developed the 10 Principles of Disability Justice to recognize the uniqueness and power of all bodyminds and to point that "[t]he histories of white supremacy and ableism are inextricably entwined, both forged in the crucible of colonial conquest and capitalist domination" (Berne, 2015, para. 11). Berne, along with Mia Mingus, Leroy Moore, Stacey Milbern, Eli Clare, and Sebastian Margaret, contest that there should be a "second wave" of the Disability Rights Movement, as the current one "simultaneously invisibilized the lives of peoples who live at intersecting junctures of oppression ..." (Berne, 2015, para. 7). Similar to Berne et al., writer and activist Vilissa Thompson created the social media hashtag \#DisabilityTooWhite in 2016 to call attention to Whiteness within the Disability Rights Movement.

\footnotetext{
${ }^{4}$ https://www.sinsinvalid.org

${ }^{5} \mathrm{http}: / /$ www.rampyourvoice.com

${ }^{6}$ https://adapt.org
} 
Journal Committed to Social Change on Race and Ethnicity | Volume 6, Issue 1 | 2020

Whereas disabled BIPOC activists have been discussing, negotiating, and engaging with intersectionality and theorizing and practicing Disability Justice for decades, academia is more recently grappling with the intersection of disability and race in knowledge production. Chris Bell (2006) called for "White disability studies" to be critically reflexive about issues of race and addressing the scarcity of "scholarship by and about disabled people of color" (p. 278). Bell (2011) insisted that, to understand raced and disabled bodies and the systems that transform them, we need to engage in recovery and detection work. Similarly, since the 1970s, Deaf Studies has primarily focused on a single oppression, audism, or the marginalization of Deaf people and the over-privileging of hearing people, hearing ideology, and hearing ways of being. It has also pushed for one collective, essentialized Deaf experience. However, "to be a full academic field upholding intellectual values, scholars must broaden their focus of study to encompass diverse deaf people-diverse in communication, culture, race, and ethnicity" (Fernandes \& Myers, 2010, p. 17). Deaf and hearing Scholars of Color in Deaf Studies and other fields are continuing to answer this call by holding space and producing race and deaf-centric scholarship, which is evident throughout this special issue on Disability Justice, Race and Education. Subini Annamma, David Connor, and Beth Ferri (2013) have heeded Bell's call by formulating a theoretical framework (Dis/ability Critical Race Theory (DisCrit)) to elucidate the intersectional complexities of disability and race within education. This special issue expands on DisCrit, and the work of disabled and Deaf BIPOC activists and scholars beyond the academy.

People with disabilities are one of the largest minoritized groups, making up approximately one-fifth of the U.S. population (United States Department of Labor, n.d.). 
Journal Committed to Social Change on Race and Ethnicity | Volume 6, Issue 1 | 2020

Yet, approximately $74 \%$ of those disabilities are not visible (Connell, 2013). While the U.S. Department of Education's National Center on Educational Statistics (2011) states that approximately $11 \%$ of our college student population are students with disabilities. This percentage is always in flux, as the number of diverse students with disabilities continues to grow on campuses across the country, with veterans accounting for $21 \%$, students over the age of thirty $16 \%$, and students on the autism spectrum and those with acquired brain injury rapidly increasing in number (Evan et al., 2017). In the 20152016 academic year, $51.8 \%$ of Deaf students attending college were pursing associate degrees and most had additional disabilities, including " $8.1 \%$ were deafblind, $13.1 \%$ have ambulatory disabilities, and $30.8 \%$ had learning difficulties (e.g., learning disabilities, ADHD, ADD, or depression)" (Garberoglio et al., 2019, p. 4). Much like in the Disability Rights Movement and Disability Studies, our collective understanding of disability within higher education is often white-centered, and although this is slowly changing with the addition of more Scholars of Color within Disability and Deaf Studies, it is seldom problematized enough (Pearson, 2010) and the larger impact is not always taken seriously.

This special issue elevates BIPOC communities and intersectional-centered perspectives on disabled and Deaf communities within higher education as a way to expand our understanding of disability and the lives of disabled and Deaf students, faculty and staff. We asked contributors to think about the grassroots wisdom of on-theground activists, particularly the Disability Justice framework offered by Berne (2015), as well as academic conceptualizations such as DisCrit, and to meditate on their applicability to a higher education setting. With our own strong beliefs in Disability 
Journal Committed to Social Change on Race and Ethnicity | Volume 6, Issue 1 | 2020

Justice and CRiT walking and our hope to make this knowledge available to as many people as possible, we asked contributors to avoid the academic habit of using disciplinary jargon. If authors did use unfamiliar terminology, we asked them to provide brief definitions or explanations directly in the text or as footnotes. To allow for greater accessibility and to honor multiple ways of knowing and epistemological approaches, contributors submitted research articles, poems, and American Sign Language (ASL) videos. What follows in this special issue are submissions that, we believe, will add to the higher education literature and will assist practitioners thinking about how they can make their educational spaces accessible, inclusive, and liberating for all students.

We start the special issue with personal narratives because often times, Deaf and disabled Student of Color experiences' and educational journeys are often told through the lens of a White scholar, also known as the white gaze. To give Scholars of Color a platform to share what it means to be a racialized disabled or Deaf student in our educational system is to counter the norm and re-center and reclaim the power of telling one's story for one's self. Kat J. Stephens, a disabled Ph.D. student who identifies as an Afro-Caribbean immigrant, chronicles her experiences as a Black woman with ADHD in a poem entitled "Just a Unicorn." She describes through poetry her journey through secondary and postsecondary life without an official diagnosis and her sense of anger, loss, and relief that came when she found out she had ADHD. Similarly, writer, speaker, artist, and independent researcher Arianne Garcia describes her experience as a young Latina growing up with undiagnosed autism and dreams of being a scientist in her narrative poem "Picking a Thousand Scabs: Coping in A-Sharp." She openly shares how she interpreted her traumatic personal and educational 
Journal Committed to Social Change on Race and Ethnicity | Volume 6, Issue 1 | 2020

experiences through her neurodivergent lens. Garcia's and Stephens' contributions illustrate how some Black and Brown students with non-apparent disabilities move through educational systems undiagnosed, either because they developed ways of over-compensating for survival or because they have been written off as having inherently low IQs or being unteachable.

Dr. Carla García-Fernández, Deaf Latinx Assistant Professor of Deaf Studies, takes us through her journey of navigating linguistic and racialized oppression within her higher education experiences in her piece "Intersectionality and Autoethnography: DeafBlind, DeafDisabled, Deaf and Hard of Hearing-Latinx Children Are the Future." Using the power of autoethnography and the theory she coined, Deaf Latinx Critical Race theory (Deaf LatCrit), Dr. García-Fernández unpacks the structural barriers she faced as a graduate student, scholar and now faculty member within the classroom, within universities' disability service offices and professional academic spaces. Her work pushes us to recognize the complexities of race and language by introducing us to the impact of raciolinguistics on the educational experiences of Deaf, DeafBlind, DeafDisabled, and Hard-of-Hearing (DBDDDHH) Latinx students within higher education.

Influenced by Dr. García-Fernández's theory of Deaf LatCrit and Deaf Gain, Dr. Rezenet Tsegay Moges, a Deaf Eritrean-American full-time Lecturer in Linguistics, used these theories to influence the creation of a more strengths-based understanding of Black Deaf people and their historical educational and linguistic experiences in her piece "From White Deaf People's Adversity to Black Deaf Gain." Using a raced and Deaf lens, Dr. Moges coins Black Deaf Gain, defining it as "a new way of thinking and 
Journal Committed to Social Change on Race and Ethnicity | Volume 6, Issue 1 | 2020

re-evaluating a master narrative of historical (and on-going) oppressions of racism with antiblackness, audism, and linguicism." Black Deaf Gain allows us to reframe Black Deaf students' past educational, racialized and linguistic oppression as experiences that ironically create possibilities, thriving, and hope.

Transitioning from the personal to a critical literature review, the special issue moves to empirical research that focuses on a broader understanding of educational experiences, including Indigenous Deaf students, Queer Transgender Deaf People of Color (QTDPOC), and graduate students with disabilities. Dr. Melanie McKay-Cody is a socio-cultural and linguistic anthropologist specializing in the tribal signed languages of peoples indigenous to Turtle Island (North America), especially those under the umbrella of Plains Indian Sign Language (PISL). In her ethnographic study, "Multiply Marginalized: Indigenous Deaf Students' Experiences in Higher Education," she presents her scholarship in an ASL video and unpacks the lived experiences of Indigenous Deaf students using Indigenous methodologies. Pushing against binary identities and thinking, particularly around language and culture, Dr. McKay-Cody emphasizes the need for a decolonized research process of mutual sharing versus traditional research, which tends to take knowledge out of communities without replenishing or giving back to them in meaningful ways. She provides university and community-specific recommendations that ultimately assist us in better serving Indigenous Deaf and hearing students.

Dr. McKay-Cody's piece raises the issues of linguistic discrimination and the lack of appropriate and culturally competent interpreters, which MJ Jones picks up in their work "Where are My People? The Case for Culturally Competent Interpreters." Jones, a 
Journal Committed to Social Change on Race and Ethnicity | Volume 6, Issue 1 | 2020

transmasculine of center, Black, second-generation Filipinx interpreter of color, describes their study that explores how the experiences of Queer Transgender Deaf People of Color (QTDPOC) are impacted by the level of cultural competence of their interpreters with regards to their experiences with and knowledge of QTDPOC. Jones uses semi-structured interviews of four QTDPOC participants to illuminate the cultural and linguistic challenges they faced with interpreters while attending a Queer conference. The findings encourage the interpreting field to acknowledge the current trends and disparities impacting QTDPOC, to intentionally cultivate an inclusive curriculum for interpreting students, and to hold themselves and others accountable for their decisions as interpreters when selecting jobs and collaborating.

Focusing on how invisibility impacts students, Julie Karpicz, a Ph.D. candidate and previous assistant director for a graduate school's Disability Services office, highlights another student population that often goes unnoticed. She centers the narratives of seven graduate Students of Color and explores the ways in which they learned self-advocacy from caregivers, peers, and online communities. In addition, she examines how the support they received from institutions changed as they matriculated to graduate school and the means by which they employed self-advocacy, including non-disclosure and leaving supportive academic environments. Their experiences lend flexibility to the definition of self-advocacy. For example, the fact that self-advocacy can be context dependent and that non-disclosure can be viewed as self-advocacy rather than the absence of it, adds nuance and depth to this realm of academic dialogue.

Lastly, the special issue takes a deeper dig into the classroom and explores the role of race and disability in pedagogy. White lawyer and academic success instructor 
Journal Committed to Social Change on Race and Ethnicity | Volume 6, Issue 1 | 2020

Christina Payne-Tsoupros in her piece "A Starting Point for Disability Justice in Legal Education" urges law schools to critically examine issues of access and disclosure for disabled students as well as revisiting current disability law. By highlighting the work of attorneys and disability justice Scholar-Activists of Color Lydia X.Z. Brown, Talila "TL" Lewis, and Katherine Pérez, she provides educators in the field of law (and beyond) with initial steps on how to think about and incorporate a DisCrit framework within pedagogical approaches and curricula. In the same vein, Sam Shelton, a White doctoral student of Women, Gender, and Sexuality Studies, challenges White supremacy in disability education through anti-racist teaching and action, in their piece "Disability Justice, White Supremacy, and Harm Reduction Pedagogy: Enacting Anti-Racist Crip Teaching." Shelton situates the borrowed concept of harm reduction by prioritizing safety and healing, seeking to understand and resolve underlying causes of harm as well as to connect to multiple marginalized communities that span from disability, racialized minorities, Queer, Trans*, poor and sex workers. Shelton employs harm reduction in an educational setting by outlining an intersectional, anti-racist, decolonial Disability Justice pedagogy that requires accountability and planning.

Ultimately, the goal of this special issue was to mainly highlight the work, perspectives, expertise, and experiences of People of Color, specifically Deaf and disabled People of Color. We wanted to call on the expertise of reviewers from our community to give feedback and guidance on how to create accessible and race-based scholarship. As guest-editors of this special issue in the Journal Committed to Social Change on Race and Ethnicity (JCSCORE), we worked intentionally to do what we say is needed to increase the pipeline of People of Color in Disability and Deaf scholarship 
Journal Committed to Social Change on Race and Ethnicity | Volume 6, Issue 1 | 2020

by specifically reaching out to BIPOC communities. This special issue would not have been possible without our junior female Editors of Color, Ashlee McHenry and Anna Acha, who worked behind the scenes learning about the process of writing and publishing, supporting scholars, and contributing to this issue. We hope practices like this are honored and that junior Scholars of Color will one day take our place in moving race-based disability and Deaf scholarship forward.

It is also important to mention that all of the work put into this special issue was completed during an extremely difficult, traumatic, and exhausting season for many disabled and Deaf People of Color. We cannot overstate the intellectual labor put into this issue as people navigated COVID-19 and its unknown impact as well as the Black Lives Matter (BLM) protests and the ongoing plight for racial equity for People of Color cannot be overstated. We thank the scholars and all who contributed to making this special issue possible; we recognize that it was a labor of love. As such, we lovingly offer this special issue to all and hope that it encourages dialogue and curiosity and contributes to the fight for Disability Justice, education and abolition. 
Journal Committed to Social Change on Race and Ethnicity | Volume 6, Issue 1 | 2020

\section{References}

Annamma, S.A., Connor, D., \& Ferri, B. (2013). Dis/ability critical race studies (DisCrit): Theorizing at the intersections of race and dis/ability. Race Ethnicity and Education, 16(1), 1-31. https://doi.org/10.1080/13613324.2012.730511

Bell, C.M. (2006). Introducing White disability studies: A modest proposal. In L.J. Davis (Ed.), The Disability Studies Reader (pp. 275-82). Routledge.

Bell, C.M. (Ed.). (2011). Blackness and disability: Critical examinations and cultural interventions. Michigan State University Press.

Berne, P. (2015, June 10). Disability justice - A working draft. Sins Invalid. https://www.sinsinvalid.org/curriculum

Crenshaw, K. (1991). Mapping the margins: Intersectionality, identity politics, and violence against women of color. Stanford Law Review, 43(6), 1241-1299.

Connell, W. (2013). The visible invisible disability. Invisible Disabilities Association. https://invisibledisabilities.org/invisible-no-more/the-visible-invisible-disability/.

Evan, N.J., Broido, E.M., Brown, K.R., \& Wilke, A.K. (2017). Disability in higher education: A social justice approach. Jossey-Bass.

Fernandes, J.K. \& Myers, S.S. (2010). Inclusive Deaf studies: Barriers and pathways. The Journal of Deaf Studies and Deaf Education, 15(1), 17-29, https://doi.org/10.1093/deafed/enp018

Garberoglio, C. L., Palmer, J. L., \& Cawthon, S. (2019). Undergraduate enrollment of Deaf students in the United States. Washington, DC: U.S. Department of Education, Office of Special Education Programs, National Deaf Center on Postsecondary Outcomes.

Hughes, R., \& Giles, M. (2010). CRiT walking in higher education: Activating critical race theory in the academy. Race, Ethnicity and Education, 13(1), 41-57.

Pearson, H. (2010). Complicating intersectionality through the identities of a hard of hearing Korean adoptee: An autoethnography. Equity and Excellence in Education, 43(3), 341-356.

Salinas, C., \& Lozano, A. (2019). Mapping and recontextualizing the evolution of the term Latinx: An environmental scanning in higher education. Journal of Latinos and Education, 18(4), 302-315. https://doi.org/10.1080/15348431.2017.1390464

U.S. Department of Education, National Center on Educational Statistics. (2011). Postsecondary education. https://nces.ed.gov/fastfacts/display.asp?id=60

United States Department of Labor (n.d.). Diverse perspectives: People with disabilities fulfilling your business goals. Office of Disability Employment Policy. https://www.dol.gov/odep/pubs/fact/diverse.htm 